Article

\title{
Social Media and Forced Migration: The Subversion and Subjugation of Political Life
}

\author{
Jay Marlowe \\ School of Counselling, Human Services and Social Work, University of Auckland, Auckland 1150, New Zealand; \\ E-Mail: jm.marlowe@auckland.ac.nz
}

Submitted: 10 September 2018 | Accepted: 7 March 2019 | Published: 28 June 2019

\begin{abstract}
As social media platforms and the associated communication technologies become increasingly available, affordable and usable, these tools effectively enable forced migrants to negotiate political life across borders. This connection provides a basis for resettled refugees to interact with their transnational networks and engage in political activities in novel ways. This article presents a digital ethnography with 15 resettled refugees living in New Zealand and the role of social media and transnational networks for the maintenance and creation of political lives. Taking a broad interpretation of how political and political life are understood, this article focuses on how power is achieved and leveraged to provide legitimacy and control. In particular, it examines how refugees practise transnational politics through social media as they navigate both the subjugation and subversion of power. These digital interactions have the potential to reconfigure and, at times collapse, the distance between the resettled "here" and the transnational "there". This article highlights how social media facilitates political lives as an ongoing transnational phenomenon and its implications for the country of resettlement and the wider diaspora.
\end{abstract}

\section{Keywords}

digital communication; forced migration; politics; refugee; resettlement; social media

\section{Issue}

This article is part of the issue "Refugee Crises Disclosed: Intersections between Media, Communication and Forced Migration Processes", edited by Vasiliki Tsagkroni (Leiden University, The Netherlands) and Amanda Alencar (Erasmus University Rotterdam, The Netherlands).

(C) 2019 by the author; licensee Cogitatio (Lisbon, Portugal). This article is licensed under a Creative Commons Attribution 4.0 International License (CC BY).

\section{Introduction}

Social media applications such as Facebook, WhatsApp, Skype, Viber, Instagram, Twitter and a growing list of others now deliver powerful platforms to connect forced migrants separated by distance. In particular, these tools afford refugees the means to communicate and respond to political ideas, events and crises in ways not previously possible. Through a variety of connective media, people can share and disseminate information, offer support, generate social movements and sustain political activities. These platforms powerfully facilitate the negotiation and creation of political lives and action across borders.
This article considers what digitally mediated interactions represent for resettled refugees as they negotiate political lives across geographic distance during times of rapid political, technological and social change. Following Horst (2017), the emphasis on forced migrants as political subjects remains a largely absent presence in much scholarship. In response, this study presents a digital ethnography with 15 people from refugee backgrounds living in New Zealand to highlight how digital technologies influence and enable political lives. Focussing on how social media can sustain ongoing transnational networks and relationships, the article examines the subjugation and subversion of power as refugees negotiate ongoing transnational political activities and commitments through everyday life. 


\section{Forced Displacement, Politics and Digital Connection}

Social media provides a number of platforms to engage in and debate political issues through text-based, audio, audio-visual, synchronous and asynchronous formats. Such interactions are mediated through Facebook posts, Twitter hashtags, WhatsApp encrypted chats and numerous others. Benkler (2006) suggests that these digital spaces represent a "networked public", providing a new space to discuss social and political issues. Connected across distance through the digital environment, this networked public has the potential to convey debates to large audiences in rapid and persuasive ways that range from the European refugee "crisis", the integration of refugees, the securitisation of borders and the politics of asylum. Such platforms offer individuals and groups (defined within various social locations and value positions) to engage with current events, disseminate news and mobilise forms of social action.

The United Nations High Commissioner for Refugees ([UNHCR], 2018) estimates that 68.5 million people are currently forcibly displaced, a number which underscores the massive scale of physical separation from family, friends and community. Despite this dislocation, mobile communication technologies provide the opportunity for ongoing connection across geographic distances. Such developments are particularly illustrated by the UNHCR (2016) report entitled "Connecting Refugees" that highlights how $2 \mathrm{G}$ and $3 \mathrm{G}$ mobile coverage is now available in many sites where forced migrants seek refuge in camps and urban centres. The "networked effects" (Benkler, 2006) of increasingly, though unevenly, available, affordable and usable communication pathways mean that these technologies have greater reach and potential to connect and digitally reunite forcibly displaced people as more are able to join their associated networks.

Over the last five years, the UNHCR has submitted between 65,000 to 163,000 cases for resettlement-the transfer of refugees from a country of asylum to another state that agrees to provide permanent settlement. These numbers represent a durable solution for less than $1 \%$ of the world's current forced migrants. Information communication technologies, however, provide potential to connect this minority to the remaining 99\%. The UNHCR (2016) emphasises that those in displacement sites can spend up to a third of their disposable income on mobile communications. This reality signals the importance, even necessity, of remaining connected. Whilst the availability, affordability and usability of such communication technologies remains uneven (particularly in Africa and in rural sites of displacement), it heralds new ways that displaced people can practise transnational lives and politics in ways not previously possible.

Powerful actors shape refugees' opportunities for safety and belonging that include states, institutions, non-government organisations and receiving societies.
A growing area of scholarship now focuses how digital communication technologies and social media provide a basis for refugees to have stronger roles as political actors-in countries of resettlement and transnationally (Alencar, 2017; Benton \& Glennie, 2016; Godin \& Doná, 2016; Marlowe, 2019). In particular, there is an increasing recognition of refugees as conscious political actors and the political nature of their flight (Horst, 2017). While the transfer of political remittances across diasporas is not a new phenomenon, the speed at which these can be provided through social media offers new transformative possibilities and extended reachfor forced migrants and powerful state actors (Krawatzek \& Funk, 2019).

The term "political" has been used in a variety of contexts, including how refugees utilise social media to discuss policy, influence elections and engage in various forms of advocacy and activism in their country of origin and the wider diaspora (Adan et al., 2018). However, the term is used so uncritically that it often escapes definition. Taking a fairly broad interpretation of how political and political life are understood, this article focuses on how power is achieved and leveraged to influence government and associated structures that give it legitimacy and control. In particular, it examines how social media affords political inclusion and decision making that allow refugees to practise transnational politics within, and beyond, national borders.

As people engage online, they are able to form assemblages or groups with shared interests. These assemblages and the rules that govern its membership may be relatively stable or incredibly dynamic. In particular, it is necessary to examine how power is exercised through the specific platforms (i.e., prohibiting or censoring content) and by its members (administrator rights to include/exclude participants, defining rules of engagement, determining the flow of resources, providing support, etc.). The political activities that such groups can achieve range from the mobilisation of ideas, sharing resources and information, generating and coordinating large-scale social movements amongst many othersat times outside the control and awareness of powerful actors.

Schradie (2015) illustrates through the concept of organising ideology that digital activism can be directed to a variety of stakeholders, which can yield different political outcomes. In some cases, digitally mediated interaction can predominantly have a bottom-up approach that is participatory and tries to mobilise the masses. In others, often through more top-down orientations, online strategies are used as direct conduit to engage with powerful and influential structures. These different political strategies can significantly shape the outcomes of social media campaigns. Thus, the access and use of digital platforms highlights the complex terrain and possible affordances that social media can provide (Leung, 2018).

For instance, the Arab Spring that began in Tunisia and spread to numerous other countries was, in many 
ways, facilitated by the smart phone and the loading of data onto various social media platforms (Breuer, Landman, \& Farquhar, 2015). During the 2011 Egyptian protests that began in Tahrir Square, half of the protestors communicated the event through social media and their phones to distribute content (Tufekci \& Wilson, 2012). Scholars demonstrate how social media has been utilised to inform and respond to the European refugee "crisis" through initiatives such as \#RefugeesWelcome and others that promote campaigns of fear and misunderstanding (Barisione, Michailidou, \& Airoldi, 2017).

Within countries of resettlement, numerous studies acknowledge the importance of social media to facilitate local bridging forms of social capital to assist with integration and transnational forms of bonding capital that connect proximal and distant networks (Alencar, 2017; Gillespie, Osseiran, \& Cheesman, 2018; Leurs, 2017; Marlowe, 2018). Adan et al. (2018) found, in a study of 100 Afghans living in the United Kingdom that nearly all of them closely followed Afghan-based politics and that some had begun lobbying for particular leaders to influence elections. This report also highlights how Somalis settled in Sweden engage with more than 6,000 members of the diaspora to discuss politics and developmentrelated issues occurring in Somalia. These studies illustrate how social media can powerfully connect people to homelands, the wider diaspora and at times, local communities in resettlement contexts.

These interactions support the formation of a counter-public, a group that comes together to challenge dominant discourses, policy positions or values (Fraser, 1990). For refugees, social media can provide the medium to engage with an increasingly intimate, textured and influential transnational counter-public to respond to political events occurring back home. It also provides a "digital escape" whereby refugees can source cultural and social capital that may not be readily accessible in the geographic location where they live (Gifford \& Wilding, 2013). These trends highlight how the "connected migrant" is able to maintain transnational links and relationships that defy proximate geography and censorship-people can incorporate such networks and political commitments in instantaneous, intimate and ongoing ways (Diminescu, 2008).

The "openness" of such platforms, however, does not always promote inclusivity. Numerous studies caution the role of social media to support integration outcomes and a sense of belonging. These concerns range from limiting refugees' commitments and activities in everyday public life in settlement contexts to how state actors can use these tools for surveillance, mass communication and to exert influence and control (Gillespie et al., 2018; Loh, 2016; Maitland, 2018). Other scholars have noted how diaspora networks can potentially inflame tensions and destabilise peace-building activities where diaspora networks can play both "constructive" and "destructive" roles (Brinkerhoff, 2008; Orjuela, 2008; Wilcock, 2018).
While social media opens new forms of communication and potential virtual spaces for forced migrants to engage in political lives, it is also necessary to acknowledge how these tools significantly extend the reach and influence of the state. Glasius' (2018) work on "extraterritorial authoritarian practices", for instance, powerfully illustrates how regimes can expand their territorial control as social media increasingly influences dominant debates and representations that advance regime interests across borders. Michaelsen's (2018) work illustrates this trend by presenting how the Iranian state used transnational communication as a way of controlling and monitoring the activities of exiles (horizontal voice) and influencing international spaces and relations (vertical voice). It clearly highlights the scale and potential of social media platforms to wield enormous power and control. Moss (2018) refers to such practices as "digitally-enabled transnational repression".

The speed and accessibility that ideas can be communicated creates contexts where political activity can be subjugated by the state, but it also supports opportunities where people can subvert such power and innovate around it. These dynamics have stimulated the development of complex social and political webs as many refugees find themselves simultaneously connected with the physical location of "here" and their transnational "there" (including the homeland). It is within this awareness and context that this study examines how resettled refugees engage as transnational political actors through a politics from below and a politics from above to navigate power structures, belonging and everyday life.

\section{Context and Study Design}

New Zealand currently resettles 1,000 refugees as part of its formal resettlement programme each year. Social media can potentially digitally reunite these relatively small numbers across significant geographic distancein this case across the seas. This article presents a digital ethnography (Murthy, 2008) of how 15 people from refugee backgrounds who have resettled in New Zealand engage in political lives through social media and what it means to be connected to their countries of origin, diaspora networks and country of settlement. Alongside regular informal online meetings, the study data include 50 online interviews (Skype, Viber or WhatsApp), two surveys and 472 social media diaries collected over 12 months. These ongoing interactions provided insight into how participants incorporated political interactions and activities through social media as it related to elections, conflicts, participating in rallies, human rights activity and other political events. Using a constructivist grounded theory methodology and informed by the constant comparative method (Charmaz, 2006), it was possible to understand and theorise how participants' political lives took shape through the social media environment over time. This was achieved through the initial and focussed coding processes that helped to generate 
categories related to political lives and the main concept of negotiating power in everyday political lives. All data were imported into NVivo for the focused coding process to manage the large amount of qualitative data to ensure findings were theoretically saturated across participants and various data sets. This iterative process over time was supported through subsequent interviews as a form of theoretical sampling, memo writing and informal online interactions.

Eight females and seven males participated in the study from a range of ethnonational backgrounds. Most participants were well educated and all could communicate in English to participate in the interviews and write the online diaries. They were living across New Zealand in the main refugee resettlement localities: Auckland, Wellington, Christchurch, Nelson and Palmerston North.

Each participant completed three to four interviews and wrote regular social media diaries in Qualtrics about how they were using social media, with whom and for what reasons. These ongoing forms of data collection and points of interaction provided the basis for theoretical sampling. Refugee-based organisations advertised opportunities to participate in the study as a form of third-party recruitment. Interested individuals then contacted the principal investigator who then established their social media practices and level of interaction with transnational networks. Two participants did not complete the study because the university decided halfway through data collection that participants must be paid for their time instead of providing them with grocery vouchers (value of up $\$ 200$ per month). The associated tax implications meant that these participants chose not to continue when the university (as opposed to the ethics committee) imposed this requirement. The study received ethics approval from the associated tertiary institution and required an additional two amendments to follow the emergent analysis to ensure that theoretical sampling related to the negotiation of political lives.

\section{Findings}

The exercise and negotiation of power plays an integral role in determining how people are able to be political. This section is divided into three parts: politics from below; politics from above; and everyday political lives. The participant quotes identify the person by number and at times by ethno-national identification only if they agreed to share this information due to concerns of safety for themselves and/or their transnational networks. Comments about gender and other social locations are made more generally in the sections below and the discussion that follows.

\subsection{Politics from Below-Subversion}

Participants identified social media as a tool to subvert powerful structures and participate in political activities relating to social change, awareness and action. While the state's power to surveil was something that all participants acknowledged, many found innovative approaches to maintain political lives and activities. One participant notes how they challenged power structures by working with those in government who were secretly supporting resistance efforts:

Those who are in the [government] system use social media to convey a message. Even if it is top secret, they would use this and then they will not be caught. We share information because in some ways we are trying to keep peace and then try to calm down the situation [in home country] if it's too high. We try to keep the momentum in that way. (Participant 7, country not disclosed)

Yeah, I started a feminist group on social media. A lot of my friends that are feminists have liked that page and even people that I don't even know have liked the page so that keeps me connected with a lot of people with the same passion as me and the same drive as me in that specific subject. (Participant 2, Eritrea)

In another form of transnational political activity, a participant notes how they administer group chats on Viber and WhatsApp to reduce ethnic tensions in South Sudan.

It is daily I have to monitor people....Three days ago I shut it down [group chats on Viber and WhatsApp] because some people complained that there were people sneaked in who might be spies.... noticed that some government agents using social media under a different name. I didn't know them and then I would be told this is a spy. It's not easy to identify but you have a network too to identify them. (Participant 3, South Sudan)

Other participants spoke of how they fed misinformation to undercover state agents to confuse them and obfuscate power structures. They found approaches to subvert the state's extended reach and influence on digital platforms.

The South Sudanese diaspora has been recognised as a "global internet warriors" (LeRiche, 2016) due to their transnational reach to respond to ethnic tensions related to the ongoing civil war-for better and worse. As this participant acknowledges:

I was identified as an "internet warrior" and I accept that title. Because what we do, when the war broke, those vulnerable people we used to transport them because a lot of them were killed. Sometimes if I post I may put a picture in there and people will comment...start writing comments about that. I'm so careful that I should not say anything that can incite a war. That's what I don't want to do. (Participant 3, South Sudan) 
What is clear is that involvement on social media can escalate and de-escalate possibilities for violence and provide opportunities for both safety and security. It is also evident that several participants used social media as a means of communicating to international NGOs and supra-national organisations to signal necessary responses to human rights violations and atrocities:

Last time, I contacted Amnesty International to help them [people in Darfur]. Even from here, from New Zealand. Amnesty International was involved and communicated with me here to support them. (Participant 1, Sudan)

For the participants who were highly active on social media (at times online more than six hours a day), they noted how they strategically used particular social media apps. For some, platforms such as WhatsApp and Telegram provided encrypted communication that made surveillance more difficult. At other times, these same participants would disseminate information and the communication of ideas to a wider audience through Facebook and Instagram for greater impact.

I am focusing on our history [on Facebook] because the young generation have not enough information about our history. For example, how the Iranian government attacked our land for standing against the Iranian government. And what's our responsibility towards our people, how we can make our history, how we can build our culture because our culture is part of our history. So we do think about those kind of things and we do continue trying to get back our rights from government. If we can, maybe...we will have [an] independent country again. (Participant 12, Iran)

I was added to a group on Viber called "Who is Hussein" which is a global movement with representatives in over 60 cities worldwide. A representative from New Zealand added about over 150 other people mainly from Afghan Community to join in and be a part of this campaign. The volunteers and representatives sign up to do multiple task from helping the homeless and feeding the hungry, to donating blood to save lives and their aim is to inspire and bring positive change to the world. I was active on this group because I wanted to give something back to the society. (Participant 5, Afghanistan, online diary)

Most of the examples provided demonstrate a politics that was focussed on the bottom-up and participatory processes that signals how social media it was used more as a tool to engage the relatively powerless than attempting to reach the powerful (see Schradie, 2015). While such activities have the potential to leverage social and political change, participants rarely used such tools as a conduit to engaging directly with the powerful. Their focus was more in trying to subvert power and hegemonic structures that currently exist. I return to these implications in the discussion.

I spoke to my friend in Nepal involved with the election activities lately. Their government is changing and hoping that the new government will bring some change which is very necessary. I don't know what it means but according to my friend, Nepal will have a federal government now hopefully for better. Social media enables me to understand many new things. It is always helping me to grow. I know that I will have many more things to learn from social media as I come across every new day. (Participant 15, Bhutan, online diary)

One of the purposes of participants' political activity was to engage with dominant framings that presented issues they saw as unjust and oppressive. The social media space effectively provided a counter-public where interested groups could challenge powerful discourses through information sharing and action. In the next example, the participant focuses on how the Australian government had framed asylum seekers in a negative light that justified oppressive offshore refugee status processing:

I posted [on Instagram] about the event I attended organised by Amnesty International to stand in solidarity with the men, women and children stuck in offshore detention centres on Manus and Nauru.... felt very strong and passionate about what I was posting because the detention of refugees on Manus and Nauru is inhumane and a clear violation of their human rights. More people need to be aware, more people need to stand out against it. As the neighbour, New Zealand has a responsibility to do more. We need to step up and point the finger when there are human rights violations regardless of where they are occurring. (Participant 10, Kurdish)

These comments support the view that settlement is an ongoing transnational experience. They live both simultaneously "here" in New Zealand and their transnational "there". It highlights how assemblages formed on social media have the potential to collapse geography, bypass censorship and connect proximal and distant networks. The same can be said of powerful state actors who also have found ways to exert power through these digital platforms.

\subsection{Politics from Above-Subjugation}

This section focuses on the politics from above or the ways in which political lives and opportunities are determined by government and powerful structures. In most cases, participants noted a concern of discussing politics as it could have negative impacts for their friends and family in their countries of origin. 
We avoid that [talking politics], honestly...because it is a big problem because every now and then-they [Government] arrest someone. If they hear you speak or talk about any political or something that they might not like, then they will arrest you. (Participant 9, Syria)

No, we are quite careful. We almost don't do anything, don't talk about any topic about politics, anything politics.... do refrain from expressing ideas more openly. (Participant 6, background not disclosed)

Sometimes some people say it's not safe to talk about security things or it's not safe to talk about politics and stuff like that. Normally we're not talking about those kinds of things and just we are talking about normal conversation. (Participant 8, Afghanistan, online diary)

For others, they noted that discussing politics could have negative ramifications for their opportunities to return home or to travel to certain countries thereby constraining their agency to fully voice their views and concerns. In this quote, the participant emphasises how their social media involvement is mediated by the awareness of potential mobility restrictions:

I find that I've stepped away from criticising the [Turkish] regime as a whole and rather to focus on particular events and acts...I have to go to Turkey to see my family. With the current situation in Iraq borders with the Kurdish airports closed there is a chance that those won't reopen for a while. (Participant 10, Kurdish)

The power of the politics from above is such is that several participants consented to participate only if their country of origin and other demographics were not disclosed. It demonstrates the perceived and actual reach of state apparatus to surveil, oppress and control within and across borders.

Yes, we can follow everything through Internet here, through news but you know, it is very critical...people there are scared and afraid to talk about such issues because they are afraid...we may talk about general issues but we don't go into details. When I talk to my friend in Europe or other countries I feel free to talk about these issues and details, but not in Syria. (Participant 9, Syria)

The associated reach meant that several participants (predominantly female) were explicitly non-political in their social media activities.

It depends [on] the secret service policy and strategy. If they want to annoy me through my relatives or my beloved, they can. They can easily find a way, especially if...I say something political on WhatsApp, they can make it...a reason to, for example arrest my friends, my family even. Yeah. So I avoid talking about politics with my family and friends there, for their safety. (Participant 12, Iran)

I stay away from politics. I'm not a politic[al] person. Just to know what's happening in my country. (Participant 8, Afghanistan)

However, even for these participants, they did note the use of code words that they could use to signify political events or when it was unsafe to have contact with their transnational networks. They offered examples where they could make reference to the government as a sporting team to seem like they were talking about everyday sports to reduce the likelihood of state surveillance and monitoring.

For these "non-political" participants, however, it did appear that political lives did creep in over the 12 months of working with them. Whether this was in relation to a local election, concerns of what was happening in their country of origin or some other development, it became clear that adopting a political life was one of strategy and at times, necessity. What becomes evident in these comments is that political lives are at times incredibly intertwined with everyday lives. While, at times, participants' activities were explicitly and purposefully "political", at others, these activities overlap with such commitments in fleeting and multipurpose ways.

\subsection{Everyday Political Lives}

Data analysis revealed that maintaining regular, often daily, social media interaction related to political activity with transnational networks was foundational to wellbeing in resettlement contexts that linked people to the country of resettlement (here) and their country of origin/residence and the wider diaspora (there). Participants were unequivocal about its role in helping them and other refugees to integrate by giving them a sense of ongoing purpose.

Social media is really one of the important life aspects nowadays in New Zealand and all over the world. Even in the conflict area nowadays are using it....We can say this is one of the most important things in the life of the people, in this era. (Participant 1, Sudan)

[Being online] made me feel like I was still a part of society and made me feel included and caught up with everyone else. Social media is a simple network that keeps you keep updated in every imperative event that happens both within New Zealand and outside New Zealand. (Participant 2, Eritrea)

I spoke to my friend in Nepal and we discussed about Nepal's political situations and the struggles every per- 
son has to go through to make a simple living. We also discussed about New Zealand's new prime minister. I told my friend about my participation in voting. (Participant 15, Bhutan, online diary)

As political activities on social media become intertwined with everyday lives, all participants noted how being connected to those they are separated from by geographical distance was essential to well-being and participation in resettlement contexts. The survey responses from participants generally showed that twelve of the fifteen estimated spending one to four hours a day on social media. This was generally supported by what was communicated in the diaries and interviews. However, on many occasions it was clear that these activities could easily extend into eight hours or more a day depending on particular cultural, political, religious or social events that were occurring. One participant demonstrated how transnational care and support is tied to political activities and discussions:

We discussed what's happening in Iraq with so called Islamic State and Mosul. Most of the men in our family are Peshmerga and away in Mosul. They were giving us updates from the ground about how bad things are in the region. We were discussing the current talk of a referendum for an independent Kurdish state and how likely that would be, the ongoing issues with Turkey and how the different Kurdish political parties that can't seem to agree about anything.... But it is very frightening to imagine how close my uncles and cousins are to the conflict and the risk[s]. (Participant 10, Kurdish)

As these interactions become increasingly inculcated into everyday lives, it also influences how participants access news. Nearly all participants said the principal way that they accessed news events and information was through their social media feeds (along with several trusted news networks). Their networks were typically composed of people who shared similar views, a high proportion of which often came from similar social locations related to age, gender and ethno-national identifications leading to a potential confirmation bias where people gravitate to perspectives that align with their values and views.

I have been using Facebook to keep on track on what's going on around the world and even in New Zealand with the election updates. I found it so much easier scrolling my news feed and glancing at the new updates which gave me quick information about elections. I don't watch TV much, so social media is how I keep on track with political matters. (Participant 2, Eritrea)

Several participants were aware of this confirmation bias as a form of interaction where access to information is shared between limited networks of "friends" on their associated social media profiles.

So I think the problem with that is unless things get shared really widely you are just preaching to people who already are open to your views. So, you are not necessarily influencing those that you perhaps need to influence. (Participant 10, Kurdish)

Participants were asked where they accessed news and this largely reinforced this confirmation bias-the predominant sources of information were through their social network channels. While participants noted trusting other news sources such as BBC, Al Jazeera, CNN and Fox News, most emphasised that news reached them most quickly through their social media feeds.

First in Facebook, then I will go on newspapers. I don't have TV in my current place. I'd rather do Facebook news. (Participant 11, Sri Lanka)

Every day, I check my Facebook and people, they are posting things about Afghanistan, about culture, about news, about events, almost about everything. (Participant 8, Afghanistan)

Yeah, if I'm concerned with something I would go on Facebook because usually that's the first place that I can use so I'm like okay, if it's on Facebook then it's actually happening. (Participant 2, Eritrea)

I'm on Twitter every day. I follow people that are working in the same area as me. I'm making sure I'm keeping up with any development. (Participant 14, Rwanda)

And finally, for some participants, where ongoing conflicts and persecution are not occurring or as prevalent in their homelands, their everyday political lives may take different shapes and engender different commitments.

The social media has brought massive changes in social life. (Participant 3, South Sudan)

In addition to providing a basis to enact their citizenship and political lives overseas, there is also evidence that participation on social media can support a sense of meaning and integration in the country of resettlement. While there are potential concerns that ongoing transnational interactions could be a disincentive to engage with everyday lives and local politics in countries of resettlement, participants were nearly unequivocal of its importance to meaningfully settle in New Zealand.

The study findings also highlight how social media effectively collapses physical geographies of distance through incorporating increasingly intimate transnational interactions and political commitments into everyday lives. It is important to recognise that the participants 
of this study were generally well educated and fluent in English. Their experiences of social media could be in stark contrast to other people from refugee backgrounds who may not have the same access to various forms of linguistic, social and cultural capital. However, participants were asked to speak on their perspectives of their ethnic based community and noted the centrality of social media for the maintenance of social relations, a sense of belonging and for providing purpose through new ways of engaging in political issues in countries of origin. They also provided examples where they taught their parents and other community members who spoke limited English to use social media with transnational networks and how this inculcated everyday transnational interactions. Thus, while the contexts and situations for refuge differ, the increasingly accessible opportunities for digital connection open further possibilities for the enactment of transnational settlement and online political action.

As was seen over the 12-month study, the articulation of political lives had ebbs and flows that responded to the everyday contexts of transnational lives. At times, these political commitments were intimately woven into people's everyday lives and at others, were largely nonexistent. In many cases, the enactment of political lives through social media facilitated counter-publics of belonging, opportunities to challenge dominant discourses and the possibility of mobilising the masses. Thus, it is clear that social media represents a communication tool that creates new opportunities for the exercise of power to subjugate particular groups. It also offers novel approaches to subvert and innovate against powerful structures, though often not directly. Such activities highlight the new affordances and cautions that communication technologies provide-effectively reshaping political lives and action.

\section{Discussion}

Social media is increasingly part of people's everyday lives and has powerful potential to shape and reinforce political ideas and practices. Whether refugees are translating news from one language to another, reposting trusted information, participating in protest or engaging in events happening back home-the reality is that refugee settlement is, for many people, an ongoing transnational experience. So too, are the ways that refugees live their political lives.

Through practices of resistance and innovation, refugees are able to forge counter-publics to dominant framings and oppressive authoritarian practices. While not arguing for some sort of digital utopia, it was clear across all participants that social media is intimately embedded in their sense of belonging that connects them from the place of resettlement to their homelands. For many, the incorporation of political lives is an important part of these interactions that highlight the need to consider refugee resettlement that occurs simultaneously with proximal and distant networks.
The data presented show that refugees can be "dual political actors" (Adan et al., 2018) where social media provides refugees the opportunity to live their lives both "here" and "there". In some instances, the space between this binary is collapsed as people live increasingly sophisticated everyday lives in more than one location through social media platforms. Alencar's (2017) work on social media illustrates how online interactions influence the experience of refugee integration and how it is communicated across society through various forms of social capital that provide opportunities to reinforce, and at times, transcend difference. It means thinking through how integration is defined as ongoing transnational commitments, relationships and activities coincide with everyday local life.

For many refugees, regular and reliable access to transnational networks is a growing and an integral part of settlement that sustains and supports people's overall well-being. The involvement of political lives provides the basis for people to connect through common language, culture and history with transnational networks. It effectively creates a space where resettled refugees are not necessarily positioned as the "other" that generate possibilities to practise a politics from below and challenge the dominant and hegemonic framings. Importantly, such interactions provide opportunities to have a voice in situations where forced migrants are often silenced. As the examples in this article illustrates, participants generally used social media to exercise political lives from a bottom-up approach but seldom employed it as a means to communicate with or influence structures directly. Their political lives often tried to avoid the state or perhaps to misinform it, but rarely to communicate with it in a direct sense.

This study also reinforces how social media provides a pathway for powerful actors and institutions (often the state) to exert power within and across borders. Governments and other institutions can use such tools to predict population movements, collect massive amounts of personal data, convey dominant discourses and exert control that powerfully inform people's mobilities and everyday lives. However, state actors can also use online technologies in liberating and empowering ways. There are numerous examples of how government and other institutions are using social media platforms to help refugees integrate and inform them of their rights (Adan et al., 2018; Gillespie et al., 2018; Maitland, 2018). Such initiatives can provide a foundation for the enactment of local and transnational political lives.

Current examples include supporting Canada's private sponsorship programme through digital communication technologies, apps across Europe designed to assist refugees and asylum seekers with integration, and groups such as Techfugees that look for digital solutions to the problems associated with forced displacement (see Benton \& Glennie, 2016; Dekker, Engbersen, Klaver, \& Vonk, 2018; Lepeska, 2016). Receiving states can also engage with resettled refugees to assist them with elec- 
toral processes and other forms of decision making (see Adan et al., 2018). While such actions can obviously connect people dislocated and separated by distance, it may also improve resettled refugees' sense of place in their host country-something powerfully emphasised by the participants in this study. Such processes could create pathways for greater social inclusion and participation in local politics and communication across difference. The associated possibilities include training people in how to use social media, addressing the sources of digital inequality, subsidising costs to access the internet and providing development assistance to develop and build necessary infrastructure to connect refugees' proximal and distant networks.

It is important to stress that technological solutions to dislocation and political voice are not necessarily the best, or even desirable, solution. There were assumptions that the web 2.0 would democratise information and broaden debate-including in the area of politics. The confirmation bias of people seeking views that support entrenched political and value positions is a prime example. Many social media feeds are populated with people "like us" that create echo chambers, which can stifle necessary debate and proliferate fake news as "truth" (Sunstein, 2018). The reality is that "friends" interact on a given platform because they often have similar values. It means that information can become incredibly homogenised and narrowed. These networked publics can limit opportunity to engage with alternative perspectives-something very much needed in the heated debates that occur about displacement and asylum.

Digital inequality provides serious cautions about who is able to access information, support and relationships as content and opportunities are increasingly linked to digital forms of connection. In many respects, digital illiteracy can represent a new form of poverty where those who are not able to engage are increasingly left behind. Thus, as the participants in this study have high levels of education and English language competency, it is also necessary to recognise that the opportunities for the enactment of political lives through digital technologies is powerfully informed by its associated usability, affordability and availability. It is also necessary to acknowledge that not everyone is political. And even fewer would actively engage with online political lives in the way this article has defined it: how power is achieved and leveraged to influence government and the associated structures that give it legitimacy and control. For some, this would be because of concerns of safety and security-for themselves and their transnational relations. For others, it relates to a disinterest or reaction to previous political processes that created their forced migration journey in the first place. Despite these concerns, the increasing reality is that refugees live both "here" and "there" and that the spaces between this binary are becoming more nuanced and complex.

\section{Conclusion}

The digital environment facilitated through social media is effectively reconfiguring, and at times collapsing, the associated boundaries and borders for the realisations of political life. While the risks to participation are real due to fear of reprisal and persecution, refugees have found ways to subjugate hegemonic power and to find various forms of political involvement from information sharing to bold forms of political action and activism. Such interactions offer possibilities for peace building and political participation in countries of origin. It can also influence how resettled refugees meaningfully feel "in place" within their country of resettlement.

These developments herald a need for methodological innovation that extends beyond borders and captures the digital everyday lives of people forcibly separated and displaced. It highlights the importance of going beyond "methodological nationalism" (Wimmer \& Schiller, 2003) or the tendency to approach a research question bounded by national borders. It also signals a new ethics in practice where one must be responsive to participants and their transnational networks, particularly in situations of ongoing precarity. As online methods continue to proliferate and capture new forms of data, there is a need to consider how people's safety and well-being is ensured. These comments highlight a further commitment to ethical responsiveness when understanding how forced migrants use technology to negotiate various social locations, geographic distance, political action and craft meaningful lives and livelihoods across borders.

The fact that refugees maintain contact with their transnational networks is not a new phenomenon. The availability, accessibility and usability of social media platforms, however, opens new possibilities for the reach and shape of refugee's transnational relationships and networks. These trends also highlight that governments have powerful digital tools for surveillance, predicting migratory movements and pathways, influencing humanitarian actions, and collecting massive swathes of information. Thus, a suite of risks and reservations accompany the new possibilities and affordances of digital communications. These platforms facilitate the negotiation of everyday lives, power and relationships. Ignoring these accelerating trends fails to recognise that many refugees maintain ongoing transnational political lives. Such realities have significant ramifications for countries of origin, countries of resettlement, the wider diaspora and the possibilities of forced migration futures.

\section{Acknowledgments}

This research was supported by the Royal Society New Zealand under a Marsden Fast Start grant, ID\# 3708459.

\section{Conflict of Interests}

The author declares no conflict of interests. 


\section{References}

Adan, T., de Casanova, J.-T. A., El-Helou, Z., Mannix, E., Mpeiwa, M., Opon, C. O., . . Z Zakaryan, T. (2018). Political participation of refugees: Bridging the gaps. Stockholm: International Institute for Democracy and Electoral Assistance. Retrieved from http://www.bosch-stiftung.de/sites/default/files/ publications/pdf/2018-04/Political-participation-ofrefugees-bridging-the-gaps.pdf

Alencar, A. (2017). Refugee integration and social media: A local and experiential perspective. Information, Communication \& Society, 1-16. https://doi.org/10. 1080/1369118X.2017.1340500

Barisione, M., Michailidou, A., \& Airoldi, M. (2017). Understanding a digital movement of opinion: The case of \#RefugeesWelcome. Information, Communication \& Society, 21(11), 1588-1603, 1-20. https://doi.org/ 10.1080/1369118X.2017.1410204

Benkler, Y. (2006). The wealth of networks: How social production transforms markets and freedom. New Haven, CT: Yale University Press.

Benton, M., \& Glennie, A. (2016). Digital humanitarianism: How tech entrepreneurs are supporting refugee integration. Washington, DC: Migration Policy Institute.

Breuer, A., Landman, T., \& Farquhar, D. (2015). Social media and protest mobilization: Evidence from the Tunisian revolution. Democratization, 22(4), 764-792. https://doi.org/10.1080/13510347.2014. 885505

Brinkerhoff, J. M. (2008). Diaspora identity and the potential for violence: Toward an identity-mobilization framework. Identity, 8(1), 67-88. https://doi.org/10. 1080/15283480701787376

Charmaz, K. (2006). Constructing grounded theory. London: Sage Publications.

Dekker, R., Engbersen, G., Klaver, J., \& Vonk, H. (2018). Smart refugees: How Syrian asylum migrants use social media information in migration decision-making. Social Media + Society, 4(1). https://doi.org/10. 1177/2056305118764439

Diminescu, D. (2008). The connected migrant: An epistemological manifesto. Social Science Information, 47(4), 565-579. 10.1177/0539018408096447

Fraser, N. (1990). Rethinking the public sphere: A contribution to the critique of actually existing democracy. Social Text, (25/26), 56-80.

Gifford, S. M., \& Wilding, R. (2013). Digital escapes? ICTs, settlement and belonging among Karen youth in Melbourne, Australia. Journal of Refugee Studies, 26(4), 558-575. https://doi.org/10.1093/jrs/fet020

Gillespie, M., Osseiran, S., \& Cheesman, M. (2018). Syrian refugees and the digital passage to Europe: Smartphone infrastructures and affordances. Social Media + Society, 4(1). https://doi.org/10.1177/ 2056305118764440

Glasius, M. (2018). Extraterritorial authoritarian prac- tices: A framework. Globalizations, 15(2), 179-197. https://doi.org/10.1080/14747731.2017.1403781

Godin, M., \& Doná, G. (2016). "Refugee voices," new social media and politics of representation: Young Congolese in the diaspora and beyond. Refuge: Canada's Journal on Refugees, 32(1), 60-71.

Horst, C. (2017). Forced migration: Morality and politics. Ethnic and Racial Studies, 41(3), 440-447.

Krawatzek, F., \& Müller-Funk, L. (2019). Two centuries of flows between 'here' and 'there': Political remittances and their transformative potential. Journal of ethnic and migration studies. https://doi.org/10. 1080/1369183X.2018.1554282

Lepeska, D. (2016). Refugees and the technology of exile. The Wilson Quarterly. Retrieved from https:// wilsonquarterly.com/quarterly/looking-backmoving-forward/refugees-and-the-technologyof-exile

LeRiche, M. (2016). Facebook and social media fanning the flames of war in South Sudan. Centre for Security Governance. Retrieved from http:// secgovcentre.org/2016/07/facebook-and-socialmedia-fanning-the-flames-of-war-in-south-sudan

Leung, L. (2018). Technologies of refuge and displacement: Rethinking digital divides. Lanham, MD: Lexington Books.

Leurs, K. (2017). Communication rights from the margins: Politicising young refugees' smartphone pocket archives. International Communication Gazette, 79(6/7), 674-698. https://doi.org/10.1177/ 1748048517727182

Loh, T. (2016). Digitizing refugees: The effect of technology on forced displacement. Gnovis, 16(2), 49-57.

Maitland, C. (2018). Digital lifeline? ICTs for refugees and displaced persons. Cambridge, MA: MIT Press.

Marlowe, J. (2018). Belonging and transnational refugee settlement: Unsettling the everyday and the extraordinary. London: Routledge.

Marlowe, J. (2019) Refugee resettlement, social media and the social organisation of difference. Global Networks. https://doi.org/10.1111/glob.12233

Michaelsen, M. (2018). Exit and voice in a digital age: Iran's exiled activists and the authoritarian state. Globalizations, 15(2), 248-264. https://doi.org/10. 1080/14747731.2016.1263078

Moss, D. (2018). The ties that bind: Internet communication technologies, networked authoritarianism, and 'voice' in the Syrian diaspora. Globalizations, 15(2), 265-282. https://doi.org/10.1080/14747731. 2016.1263079

Murthy, D. (2008). Digital ethnography: An examination of the use of new technologies for social research. Sociology, 42(5), 837-855. https://doi.org/10.1177/ 0038038508094565

Orjuela, C. (2008). Distant warriors, distant peace workers? Multiple diaspora roles in Sri Lanka's violent conflict. Global Networks, 8(4), 436-452. https://doi. org/10.1111/j.1471-0374.2008.00233.x 
Schradie, J. (2015). Qualitative political communication | labor unions, social media, and political ideology: Using the internet to reach the powerful or mobilize the powerless? International Journal of Communication, 9, 1985-2006.

Sunstein, C. R. (2018). \#Republic: Divided democracy in the age of social media. Princeton, NJ: Princeton University Press.

Tufekci, Z., \& Wilson, C. (2012). Social media and the decision to participate in political protest: Observations from Tahrir Square. Journal of Communication, 62(2), 363-379. https://doi.org/10.1111/j. 1460-2466.2012.01629.x

United Nations High Commisioner for Refugees. (2016). Connecting refugees: How internet and mobile connectivity can improve refugee well-being and transform humanitarian action. Geneva: United
Nations High Commisioner for Refugees. Retrieved from http://www.unhcr.org/publications/ operations/5770d43c4/connecting-refugees.html

United Nations High Commisioner for Refugees. (2018). Global trends: Forced displacement in 2017. Geneva: United Nations High Commisioner for Refugees. Retrieved from www.unhcr.org/globaltrends

Wilcock, C. (2018). Why are migrant campaigns different from homeland campaigns? Understanding belonging in context among UK-Sudanese activists. Global Networks. https://doi.org/10.1111/glob.12216

Wimmer, A., \& Schiller, N. G. (2003). Methodological nationalism, the social sciences, and the study of migration: An essay in historical epistemology. International Migration Review, 37(3), 576-610. https:// doi.org/10.2307/30037750

\section{About the Author}

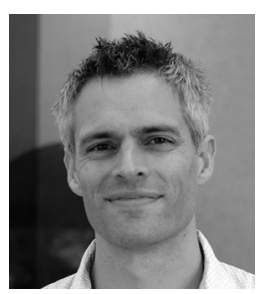

Jay Marlowe is a Rutherford Discovery Fellow and an Associate Professor in the School of Counselling Human Services and Social Work. His research focuses on refugee settlement futures as it relates to migration policy, transnational connection, use of technology and the implications for belonging within an increasingly, but unevenly, mobile world. He has a new book published with Routledge titled Belonging and Transnational Refugee Settlement. 